\title{
Factors Affecting Characteristic Length of the Combustion Chamber of Liquid Propellant Rocket Engines
}

\author{
TAJ WALI KHAN*, AND IHTZAZ QAMAR* \\ RECEIVED ON 22.02.2018 ACCEPTED ON 17.08.2018
}

\begin{abstract}
Optimum characteristic length of the combustion chamber of liquid rocket engine is very important to get higher energy from the liquid propellants. Characteristic length is defined by the time required for complete burning of fuel. Combustion reactions are very fast and combustion is evaporation dependent. This paper proposes fuel droplet evaporation model for liquid propellant rocket engine and discusses the factors which can affect the required size of characteristic length of the combustion chamber based on proposed model. The analysis is performed for low temperature combustion chamber. A computer code based on proposed model is generated, which solve analytical equations to calculate combustion chamber characteristic length under various input conditions. The analysis shows that characteristic length is affected by combustion chamber temperature, pressure, fuel droplet diameter, chamber diameter, mass flow rate of propellants and relative velocity of the droplet in the combustion chamber.
\end{abstract}

Key Words: Fuel Droplet Evaporation, Spalding Numbers, Characteristic Length, Characteristic Velocity, Liquid Rocket Engine.

\section{INTRODUCTION}

$\mathrm{E}$

xperimentation, for performance evaluation and reliability of liquid rocket engine is very difficult and expensive task. One cannot afford to do multiple tests to optimize different parameters of the engine; therefore, understanding of the factors which can affect performance of the liquid rocket engine is very important.

Characteristic length is one of the important parameters of the combustion chamber of liquid rocket engine. Characteristic length of the combustion chamber can be tanken as the length of the tube equal in diameter to the diameter of the throat of combustion chamber and volume of the pipe equal to volume of the combustion chamber. Characteristic length of the combustion chamber is calculated by dividing volume of the chamber by area of the throat. Mathematically,

$$
L^{*}=\frac{V_{c c}}{A_{t}}
$$

$\mathrm{V}_{\mathrm{cc}}$ is volume of the chamber up to throat. Characteristic length has normally value between 0.8 and 3 meter. It can be higher in some conditions. It is even higher for some

Authors E-Mail: (tajwalikhan1@yahoo.com, taj.wali01@ist.edu.pk, ihtzaz.qamar@ist.edu.pk)

* Department of Aeronautics \& Astronautics, Institute of Space Technology, Islamabad, Pakistan. 
monopropellant [1]. Normally characteristic length for a new combustion chamber is selected on the basis of experiments or data available in literature of successful combustion chambers. Values of characteristic lengths for some propellants are shown in Table 1 [2-3].

Characteristic velocity is affected by characteristic length, which is a measure of the combustion performance of the combustion chamber. Characteristic velocity increases with increase in characteristic length up to a level. Any further increase in characteristic length will not increase characteristic velocity of the combustion chamber. Increasing characteristic length beyond optimum value will decrease overall engine performance.Larger characteristic length results in more weight and more volume of the chamber. More volume of the chamber results in more inside surface area of the chamber, which need to be cool. Larger chamber have more pressure drop across cooling jacket of the chamber. In case of larger surface area for heat transfer more heat is transferred from hot gas to cooling propellant in cooling jacket, which can result in evaporation of propellant in cooling jacket. Evaporation of propellant in cooling jacket can damage combustion chamber. Larger characteristic length increases heat losses from the chamber. Increase in the weight of the combustion chamber is afforded at the cost of the pay load of the launch vehicle. Increase of one $\mathrm{kg}$ of weight of engine causes reduction of one $\mathrm{kg}$ of pay load if the engine is the last stage of the launch vehicle.

Mulkey et. al. [4] reported decrease in characteristic velocity with increase in characteristic length without insulation due to heat losses through copper wall of the chamber.

Jo et. al. [5] developed and tested $1200 \mathrm{~N}$ bipropellant rocket engine. They perform test with different type of injector pattern and characteristic length. They conducted tests with characteristic length of $0.95,1.07$ and $1.2 \mathrm{~m}$ with variation in equivalent ratio. They concluded that there is increase in characteristic velocity with increase in characteristic length up to $1.2 \mathrm{~m}$. They did not report the value of characteristic velocity for characteristic length above $1.2 \mathrm{~m}$.

Kim et. al. [6] conducted test of $70 \mathrm{~N}$ hydrazine thruster with different characteristic length. They did not measure combustion chamber pressure. They check performance on the basis of thrust measured.

TABLE 1. APPROXIMATED CHARACTERISTIC LENGTH FOR DIFFERENT PROPELLANTS [2-3]

\begin{tabular}{|c|c|c|c|c|c|}
\hline $\begin{array}{c}\text { Propellant } \\
\text { Combination }\end{array}$ & $\begin{array}{c}\text { Chamber } \\
\text { Characteristic } \\
\text { Length } \\
(\mathrm{m})\end{array}$ & $\begin{array}{c}\text { Propellant } \\
\text { Combination }\end{array}$ & $\begin{array}{c}\text { Chamber } \\
\text { Characteristic } \\
\text { Length } \\
(\mathrm{m})\end{array}$ & $\begin{array}{c}\text { Propellant } \\
\text { Combination }\end{array}$ & $\begin{array}{c}\text { Chamber } \\
\text { Characteristic } \\
\text { Length } \\
(\mathrm{m})\end{array}$ \\
\hline $\begin{array}{c}\text { Chlorine } \\
\text { Tri Fluoride/Hydrazine- } \\
\text { Based Fuel }\end{array}$ & $0.76-0.88$ & $\begin{array}{c}\text { Liquid } \\
\text { fluorine/hydrazine }\end{array}$ & $0.6-0.7$ & $\begin{array}{c}\text { Liquid fluorine/liquid } \\
\text { hydrogen }\end{array}$ & $0.63-0.76$ \\
\hline $\begin{array}{c}\text { Hydrogen } \\
\text { Peroxide/RP-1 }\end{array}$ & $1.5-1.8$ & $\begin{array}{c}\text { Hydrogen } \\
\text { peroxide/RP-1 }\end{array}$ & $1.5-1.8$ & $\begin{array}{c}\text { Nitric acid /hydrazine- } \\
\text { base fuel }\end{array}$ & $0.76-0.88$ \\
\hline $\begin{array}{c}\text { Nitrogen } \\
\text { Tetroxide/Hydrazine- } \\
\text { Base Fuel }\end{array}$ & $0.76-0.88$ & $\begin{array}{c}\text { Liquid } \\
\text { oxygen/ammonia }\end{array}$ & $0.76-1.02$ & $\begin{array}{c}\text { Liquid oxygen/liquid } \\
\text { hydrogen }\end{array}$ & $0.76-1.02$ \\
\hline $\begin{array}{c}\text { Liquid } \\
\text { Oxygen/RP-1 }\end{array}$ & $1.02-1.27$ & $\begin{array}{c}\text { Liquid oxygen/ethyl } \\
\text { alcohol }\end{array}$ & $2.5-3$ & Fluorine/hydrogen & $0.55-0.65$ \\
\hline $\begin{array}{c}\text { Nitric } \\
\text { Acid/Hydrazine }\end{array}$ & $0.75-0.9$ & $\begin{array}{c}\text { Nitrogen tetroxide } \\
\text { /hydrazine }\end{array}$ & $0.75-0.9$ & & \\
\hline
\end{tabular}

Mehran University Research Journal of Engineering \& Technology, Volume 38, No. 3, July, 2019 [p-ISSN: 0254-7821, e-ISSN: 2413-7219] 
Researchers have worked on the effects of characteristic length on the performance of liquid rocket engine but very limited work is reported in literature. In most of the cases the available work is only experimental or very old models have been used to predict effects of characteristic length on the performance of liquid rocket engines. Detail theoretical work along with connected experimental work is missing in literature. A model to predict characteristic length of the liquid rocket engine is required.

Table 1 showing values of characteristic length for various propellants which is misguiding. Table 1 shows only effects of type of propellant combination on the characteristic length and effects of all other parameters are missing. Characteristic length of a combustion chamber is directly related to the time required for complete combustion/evaporation of the propellants. The time required is normally referred as residence time. More characteristic length means more residence time provided to propellants. All the factors which affects the required residence time will affect characteristic length. Residence time required is not only dependent on the type of propellants. It is dependent upon the condition provided in combustion chamber and condition at which propellant is injected in to the combustion chamber. Reaction time is very fast and time required is mainly dependent on time required for evaporation of the droplet.

Characteristic length is given as follow [7].

$L^{*}=\frac{m}{\rho_{g} A_{t}} t_{r e s}$

Mass flow rate is selected on the basis of thrust required from the combustion chamber and specific impulse of the propellants used. Combustion performance gets improved on higher combustion chamber pressure. Combustion chamber pressure is dependent on mass flow rate, mixing ratio throat diameter and flame temperature. Combustion chamber pressure is also decided on the basis of manufacturing process of the combustion chamber. Pressure in cooling jacket of the combustion chamber is much more than combustion chamber pressure. Cooling jacket should sustain under such higher pressure.

\section{COMBUSTION IN LIQUID ROCKET ENGINE}

Combustion in liquid rocket engine is non-premixed turbulent diffusion combustion. Diffusion plays important role so; performances of the combustion in liquid rocket engines are dependent on good mixing and high diffusion rate. Atomization play important role, smaller the droplet diameter, less is the time required for evaporation and combustion. Reaction time in combustion of liquid rocket engine is very fast due to higher temperature and most of the time required for combustion is evaporation and mixing time.

In spray combustion, combustion is controlled by fuel droplet evaporation rate. The speed of evaporation depends on chamber temperature, chamber pressure, initial fuel droplet temperature, size of fuel droplet, type of propellants, relative velocity of fuel droplet, ambient gas transport properties and turbulent intensity [8].

Fig. 1 shows schematic diagram of chamber. Fig. 1 shows that there are zones in combustion chamber. As combustion is non-premix so, a mixing zone is required and combustion takes place after mixing. Stability of combustion is also dependent on proper mixing of fuel and oxidizer. Hot gas temperature inside combustion chamber is high enough in main chamber, it is more 
than $3000 \mathrm{~K}$ in majority cases. Temperature of hot gas is controlled through propellant selection, oxidizer to fuel mixing ratio, chamber pressure and atomization technique etc. Walls of the chamber cannot sustain such high temperature if it is not cooled. Velocity of hot gas in combustion chamber is sub-sonic, it get sonic at throat and is supersonic in divergent nozzle part. Due to high velocity of hot gas and small area at throat, heat flux is high at throat. Different techniques are used to cool chamber wall. One of the most important and well known is regenerative cooling as shown in Fig. 1. In majority cases fuel is used for regenerative cooling by passing fuel with velocity range from $6-24 \mathrm{~m} / \mathrm{sec}$ through jacket around inner wall of chamber [2]. Fuel passing through cooling jacket, takes away heat from wall.

\section{SINGLE DROPLET EVAPORATION}

Combustion takes place in gaseous phase, therefore evaporation of fuel is very important process for the performance of liquid fueled combustion systems, such as gas turbines, automobiles and propulsion systems. A lot of work has been done on the evaporation of spray and droplet evaporation [9-13].

In liquid combustion systems, the spray is dense and droplets are close to one another. Modeling or experimental study of such spray is difficult; therefore, modeling of single droplet is performed, which gives a very good picture of actual problem [14]. The modeling of evaporation of single droplet is simplification of real complex spray evaporation. Single fuel droplet is studied in past and will be studied in future in quiescent state, gas moving around the droplet and turbulent condition around the droplet.

Stagnant Condition or no Relative Movement: At stagnant condition there is no movement of the drop relative to ambient gas. Heat transfer takes place due to conduction, radiation and natural convection in such condition. Most of the work for spray or droplet evaporation is done at stagnant condition. The work of Godsave in 1950s [15] led to the quasi steady state model, which is also called $\mathrm{d}^{2}$ law.

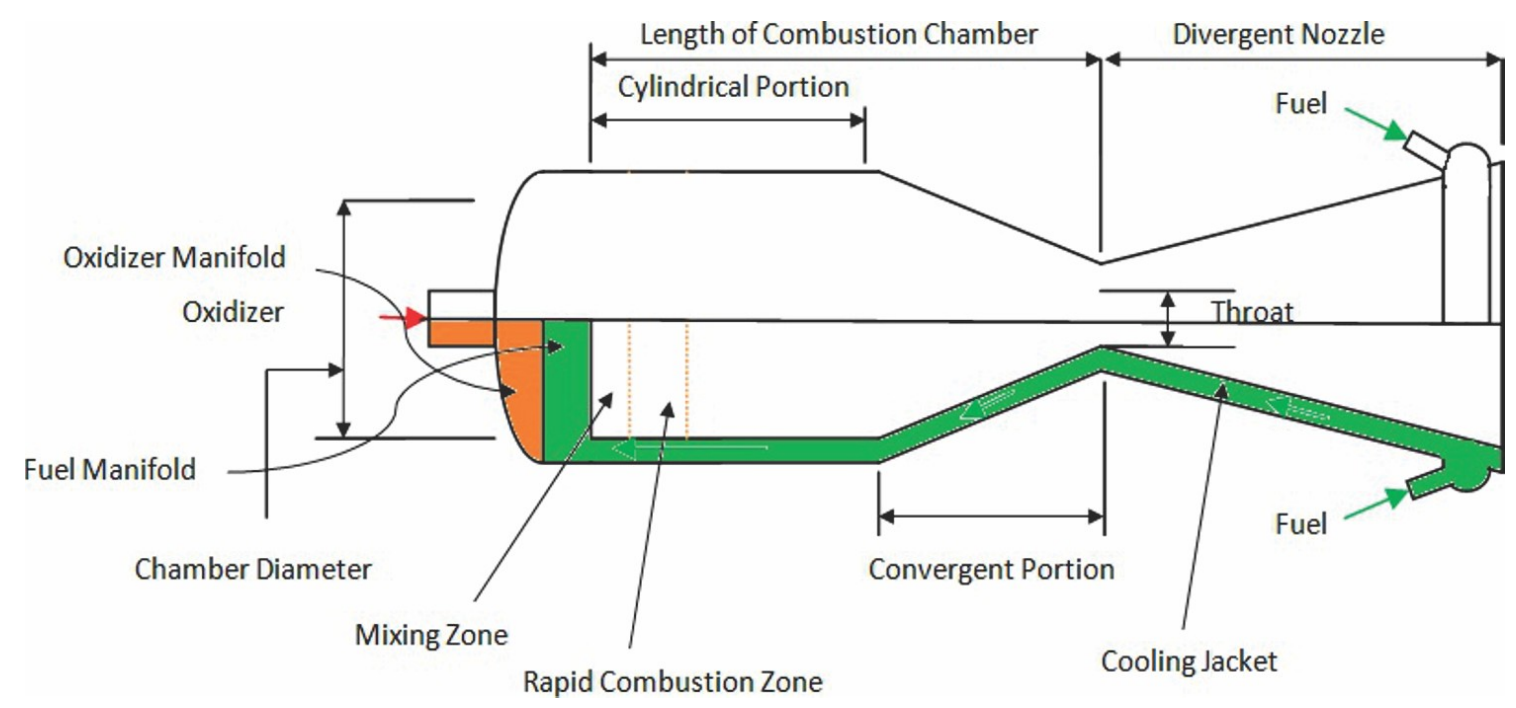

FIG. 1. COMBUSTION CHAMBER OF LIQUID ROCKET ENGINE 
Convective Conditions: When there is relative motion between droplet and ambient gases then force convection come into play its role and then heat transfer take place through conduction radiation and force convection. Relative movement helps to increase heat transfer and mass transfer so, increasing evaporation rate. Convection effects on droplet evaporation were studied by Froessling [16]. Applying Froessling correlation.

$\frac{K_{L}}{K_{q}}=1+0.27 R_{e}^{0.5} S_{c}^{1 / 3}$

Turbulent Environment: Combustion of spray is turbulent. The relative movement of hot gas around droplet affects the spray/droplets in different ways. Faeth [17] reports three different types of effects of turbulence on spray combustion. He reports droplet distribution over wide area, change of turbulence properties and change of transport properties due to motion of droplet.

Theoretical and experimental work on droplet evaporation in turbulent condition is limited. Work dealing with turbulent droplet evaporation at high temperature and pressure is almost unavailable and most of the work done is at standard temperature and pressure [18]. In Maisel and Sherwood [19] were the first who started work on effects of ambient turbulence condition on mass transfer. The entire researcher reported increase in mass transfer rate except [20]. Later on Gokalp et. al. [21], introduced vaporization Damkuhler number. Gokalp et. al. [21] reported that mass transfer is more for vaporization Damkuhler number from 0.0001-0.1. Mass transfer decreases with increase in vaporization Damkuhler number and it will not affect mass transfer if vaporization Damkuhler number is one or more than one. The findings of Gokalp at. el.[21] were verified by $\mathrm{Wu}$ et. al. [22-23].
According to Wu at. el. [22], for $0.0001 \leq \mathrm{Dav} \leq 0.1$

$$
\frac{K_{T}}{K_{u}}=D_{a_{v}}^{-0.111}
$$

Hiromitsu and Kawaguchi [24] tested Damkuhler vaporization correlation of Gokalp et. al. [21] for ambient temperature from $323-423 \mathrm{~K}$ and they found that correlation of Gokalp et. al. [21] does not work for temperature above atmospheric.

A correlation was proposed by Birouk and Gokalp [25] for turbulent effects on evaporation of droplet with zero convection mean velocity. The correlation is given below.

$$
\frac{K_{T}}{K_{q}}=1+0.02 \mathrm{Re}_{t d}^{2 / 3} S_{c}^{2}
$$

Where, $\operatorname{Re}_{t d}=q^{0.5} \frac{d_{o}}{v_{a}}$ and $\mathrm{q}=\frac{3}{2} u^{\prime 2}$ for isotropic Turbulence.

\section{ANALYTICAL DROPLET EVAPORATION MODEL FORLIQUID PROPELLANT ROCKET ENGINE}

\subsection{Assumption of the Model}

- Droplet is spherical

- Heat transfer from ambient to fuel droplet through radiation is neglected

- There is no temperature gradient in fuel droplet

- $\quad$ Fuel is pure liquid having a well-defined boiling point temperature 
- Unity Lewis number

- $\quad$ Evaporation take place in both heating and steady state phase

There are two phases for fuel droplet evaporation. One is heat up phase and other is steady state droplet evaporation phase.

During the heat phase, heat supplied from environment is partially used to raise temperature of the droplets and partially used to evaporate fuel at the surface of the droplets. Fuel droplet reaches a temperature where all of the heat is used to evaporate the droplet and no further temperature increase of droplets takes place. This is called steady state evaporation phase. The droplet surface temperature reaches wet bulb temperature and all of the heat supplied is used to provide latent heat of vaporization.

Heat transferred from environment $=$ Heat used to raise temperature of droplet + Heat used for evaporation of the droplet

Neglecting heat transfer through radiation,

$$
\dot{Q}=m_{d} C_{p l} \frac{d T_{s}}{d t}+\dot{m} L
$$

Where $\dot{Q}$ is heat transfer from ambient to droplet and $\dot{m}$ is mass evaporation rate from droplet and these are given by following Equation,

$$
\dot{Q}=\pi D k_{1}\left(T_{\infty}-T_{s}\right) N u_{d}
$$

The classical droplet evaporation rate is given by [9]

$$
\begin{aligned}
& \dot{m}=\pi D_{d} \rho_{1} \bar{D} B_{M} S h_{d} \\
& m_{d}=\rho_{l f} \frac{\rho D_{d}^{3}}{6}
\end{aligned}
$$

Putting in Equation (6),

$$
\frac{d T_{s}}{d t}=\frac{k_{1}\left[\left(T_{\infty}-T_{s}\right) N u_{d}-\frac{B_{M} S h_{d} L}{C_{p 1}}\right]}{\frac{1}{6} \rho_{f l} D_{d}^{2} C_{p l}}
$$

$\mathrm{dT}_{\mathrm{s}} / \mathrm{dt}$ is the rate of change of temperature during complete life of the droplet.

Lewis number $=\alpha / \mathrm{D}$, Assuming unity Lewis number, so $\bar{D}=\alpha$

$$
B_{M}=\frac{Y_{f s}-Y_{f \infty}}{1-Y_{f s}}
$$

Assuming fuel and oxidizer is uniformly distributed in evaporation zone of the combustion chamber and fuel mass fraction away from the droplet is equal to total fuel to total propellant mixing ratio. So,

$$
\mathrm{Y}_{\mathrm{f} \infty}=\mathrm{F}_{\mathrm{fr}}=\frac{\text { Total Fuel }}{\text { Total Propellant }}
$$

Then Equation(11) becomes,

$$
\begin{aligned}
& B_{M}=\frac{Y_{f s}-F_{f r}}{1-Y_{f s}} \\
& Y_{f s}=\left[1+\left(\frac{P}{P_{f s}}-1\right) \frac{M_{a m b}}{M_{f}}\right]^{-1}
\end{aligned}
$$

Vapor pressure, $\mathrm{P}_{\mathrm{fs}}$ at $\mathrm{T}_{\mathrm{s}}$ is calculated by using Antoine correlation [26], which is given Equation (14).

$\ln P_{f s}=A-\frac{B}{C+T_{s}}$ 
Where, A, B and C are constant depending on type of fuel.

Curvature of liquid droplets affects vapor pressure. Vapor pressure of liquid with convex curved surface is greater than liquid with flat surface. Using Kelvin Equation [27]:

$$
P_{\text {vapf }}=P_{f s} \operatorname{Exp}\left(\frac{2 \sigma V_{m}}{r_{D} R T_{s}}\right)
$$

Replacing $\mathrm{P}_{\mathrm{fs}}$ with $\mathrm{P}_{\text {vapf }}$ in Equation (13)

$\mathrm{Y}_{\mathrm{fs}}=\left[1+\left(\frac{\mathrm{P}}{\mathrm{P}_{\mathrm{fs}}}-1\right) \frac{\mathrm{M}_{\mathrm{amb}}}{\mathrm{M}_{\mathrm{f}}}\right]^{-1}$

$\mathrm{B}_{\mathrm{T}}=\frac{C_{p 1}\left(T_{\infty}-T_{S}\right)}{L(T s)}$

$\mathrm{L}(\mathrm{Ts})=L(T b p)\left[\frac{T c r-T s}{T c r-T b p}\right]^{0.38}$

So temperature $\mathrm{T}_{\mathrm{s}}$ at the surface of the droplet can be found from the Equation (19):

$$
\mathrm{T}_{\mathrm{S}}=T_{\infty}-\frac{Y_{f_{S}} L\left(T_{S}\right)}{\left(1-Y_{f s}\right) C_{P 1}}
$$

$\mathrm{Y}_{\mathrm{fs}}$ in Equation (19), is dependent on vapor pressure $\left(\mathrm{P}_{\mathrm{fs}}\right)$ on the surface of the drop and Vapor pressure $\left(\mathrm{P}_{\mathrm{fs}}\right)$ is dependent on temperature $T_{s}$. It changes with drop surface temperature $T_{s}$. So value of $T_{s}$ is calculated iteratively. Moreover, final value of $T_{s}$ should be such that both $B_{M}$ and $\mathrm{B}_{\mathrm{T}}$ converge at this temperature. $\mathrm{C}_{\mathrm{p} 1}$ Is calculated at reference temperature and reference composition, which are calculated according to one third rule of sparrow and Gregg [28] as follows:

$$
\begin{aligned}
& T_{r}=T_{\infty}+\frac{1}{3}\left(T_{\infty}-T_{s}\right) \\
& Y_{f r}=Y_{f s}+\frac{1}{3}\left(Y_{f \infty}-Y_{f s}\right) \\
& Y_{o r}=1-Y_{f r}
\end{aligned}
$$

The rate of change of mass of the droplet or evaporation rate is:

$\frac{d_{m d}}{d t}=\dot{m}$

Putting Equation (23) in Equation (10).

$$
\begin{aligned}
& \frac{d_{m d}}{d t}=\pi r R_{d} \rho \bar{D} B_{M} S h_{d} \\
& m_{d}=\rho_{l f} \frac{\pi D_{d}^{3}}{6}
\end{aligned}
$$

From Equations (24-25)

$\frac{d D_{d}^{2}}{d t}=\frac{4 \rho_{1} \bar{D}_{1} B_{M} S h_{d}}{\rho_{l f}}$

When Lewis number is unity then,

$$
\bar{D}_{1}=\frac{k_{1}}{\rho_{1} c_{p 1}}
$$

Putting values, Equation (26) becomes as:

$$
\frac{d D_{d}^{2}}{d t}=\frac{4 k_{1} B_{M} S h_{d}}{C_{p 1} \rho l}
$$

$\frac{d D_{d}^{2}}{d t}$ is change in square of the droplet diameter with respect to time.

$\frac{d D_{d}}{d t}=2 \frac{k_{1} B_{M} S h_{d}}{C_{p 1} \rho_{l} D_{d}}$

Equation (29) gives rate of change of droplet diameter during complete life of the droplet. 
Value of Sherwood number $\left.\left(\mathrm{Sh}_{\mathrm{d}}\right)\right)$ and Nusselt number $\left(\mathrm{Nu}_{\mathrm{d}}\right)$ are different at different condition and different assumptions. Many relations have been introduced by different authors to find Nusselt and Sherwood number at different conditions. Sazhin et. al. [29]compared different Equations to calculated Sherwood and Nusselt number at different conditions.

In practical application, conditions around droplets are turbulent and yearling [30] proposed correlation for Sherwood and Nusselt number for turbulent flow around the droplet, which are as follow:

$$
\begin{aligned}
& N u_{d}\left(1+B_{T}\right)^{0.7}=2+0.58 \operatorname{Re}_{d}^{1 / 2} \operatorname{Pr}_{1}^{1 / 3}\left(1+0.07 I^{0.843}\right) \\
& S h_{d}\left(1+B_{T}\right)^{0.7}=2+0.58 \operatorname{Re}_{d}^{1 / 2} \operatorname{Pr}_{1}^{1 / 3}\left(1+0.07 I^{0.843}\right)
\end{aligned}
$$

Putting,

$$
\begin{aligned}
& 2+0.58 \operatorname{Re}_{d}^{1 / 2} \operatorname{Pr}_{1}^{1 / 3}=N u_{0} \\
& 2+0.58 \operatorname{Re}_{d}^{1 / 2} \operatorname{Pr}_{1}^{1 / 3}=S h_{0}
\end{aligned}
$$

Equations (30-31) becomes,

$$
\begin{aligned}
& N u_{d}\left(1+B_{T}\right)^{0.7}=N u_{0}\left(1+0.07 I^{0.843}\right) \\
& S h_{d}\left(1+B_{T}\right)^{0.7}=N u_{0}\left(1+0.07 I^{0.843}\right)
\end{aligned}
$$

For stagnant droplet with no evaporation $\mathrm{Nu}_{0}$ is equal to 2 and $\mathrm{Sh}_{0}$ with no relative movement of the droplet with ambient is also 2 .

\subsection{Application on Combustion Chamber of Liquid Rocket Engine}

Velocity of hot gas inside combustion chamber is given by:

$$
V_{\infty}=\frac{\dot{m}}{\rho_{\infty} A_{c c}}
$$

$\operatorname{Re}_{\infty}=\frac{\rho_{\infty} V_{\infty} D_{c}}{\mu_{\infty}}$

Turbulent intensity (I) inside combustion chamber and velocity fluctuation [31]

$$
\begin{aligned}
& I=0.16 \operatorname{Re}_{\infty}^{-\left(\frac{1}{8}\right)} \\
& \dot{\boldsymbol{U}}=I V_{\infty}
\end{aligned}
$$

\section{SOLUTION ALGORITHM}

The model is applied on lower temperature combustion chamber of bi-propellants rocket engine. The propellants are liquid oxygen and kerosene. The model developed is mono-component fuel droplet evaporation model. Due to close resemblance in properties, kerosene droplet is assumed as single component of dodecane. Droplets of liquid oxygen takes very less time as compared to kerosene, therefore time taken by kerosene droplet is the time required for complete evaporation of both propellants.

The solution of the model takes place in two stages. In first stage of the model heating phase is solved and required values are calculated. In the second stage, steady state phase of the life of the droplet is solved. In steady phase there is no change in the temperature of the droplet. Solution procedure is shown in Fig. 1. Fig. 1 shows that heat up phase is ended when change in surface temperature of the fuel droplet is equal to or less than $10^{-6}$ and droplet life is finished when diameter of fuel droplet is equal to or less than $10^{-9}$. Computer Code starts with initial, given surface temperature of the droplet. Reference temperature is calculated using this initial temperature. Corresponding required values of density, viscosity, thermal conductivity, enthalpy, entropy, specific heat capacity at constant pressure and volume, pressure and etc. at that reference temperature is calculated. 
Thermodynamic values for liquid oxygen is taken from data file. Vapor pressure at the droplet surface is calculated. Fuel concentration on droplet surface along with fuel and oxidizer concentration at reference point is calculated. Spalding mass and heat transfer numbers are calculated at this temperature. Rate of change of temperature and diameter of the droplet is calculated from Equation (10) and Equation (29). If rate of change of temperature is not equal to or less than $10^{-6}$ then surface temperature is increased with increment equal to product of rate of change of temperature and a small time step. Droplet diameter, Reynolds number, Sherwood number and Nusselt number changes at each iterations. Droplet diameter remains same during a time step but changes from one step to another.

During Heat up period Spalding mass transfer $\left(\mathrm{B}_{\mathrm{M}}\right)$ number is less than Spalding heat transfer number $\left(\mathrm{B}_{\mathrm{T}}\right)$ as shown in Fig. 2, because heat transfer to droplet is used to raise temperature of droplet and for evaporation of droplet but in steady phase all of the heat is used to transfer mass from the surface of the droplet. Fig. 2 shows that $B_{M}$ and $\mathrm{B}_{\mathrm{T}}$ converges at temperature of $500 \mathrm{~K}$. Figs. 3-4 show fuel droplet diameter and surface temperature in heating phase. Figs. 3-4 show droplet diameter and droplet surface temperature respectively, in heating phase. Calculation for steady state starts after heat up period. Droplet surface temperature and diameter of the droplet after heat up phase is used in steady state as initial value of droplet diameter and droplet surface temperature. Total time consumed by a droplet for complete evaporation is the sum of the droplet heat up time and time taken in steady state droplet evaporation.

Fuel droplet surface temperature and diameter during its life is shown in Figs. 5-6 respectively. It is sum of time spend in heat up phase and steady state phase. Total evaporation time required for complete droplet evaporation is used to calculated characteristic length of the combustion chamber. It is clear from comparison of
Figs. 4-5 that steady phase is very short as compare to heating phase.

\section{RESULTS AND DISCUSSION}

The developed model is applied on low temperature combustion chamber with different input conditions. The output results showing the effects of input condition on characteristic length are shown. Fig. 7 shows increase in droplet evaporation time and characteristic length with increase in droplet velocity up to a point and then start

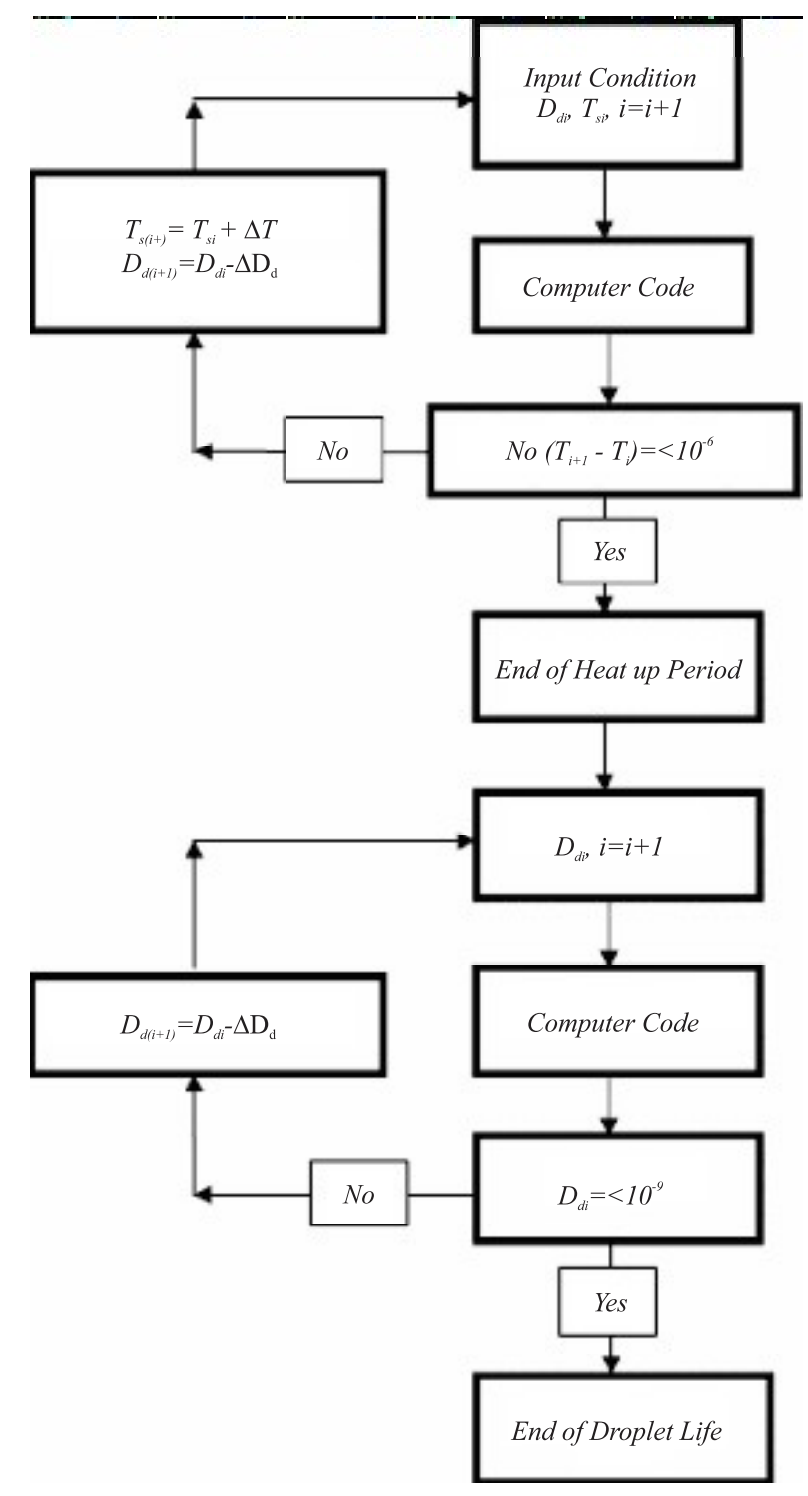

FIG. 1. SOLUTION PROCESS BLOCK DIAGRAM

Mehran University Research Journal of Engineering \& Technology, Volume 38, No. 3, July, 2019 [p-ISSN: 0254-7821, e-ISSN: 2413-7219] 
decreasing. Fuel droplet evaporation rate increases with increase in relative velocity not actual so as droplet velocity increases, it reduces relative velocity between droplet and hot gas. Relative velocity is zero at peak point in Fig. 7. Reduction in relative velocity reduces convection coefficient, so required time increases.
Fig. 8 shows that effect of chamber pressure on characteristic length. Requirement of characteristic length is more when droplet diameter is greater. Size of characteristic length is increasing with decrease in chamber pressure. Droplet evaporation is fast at higher pressure which results in smaller characteristic length.

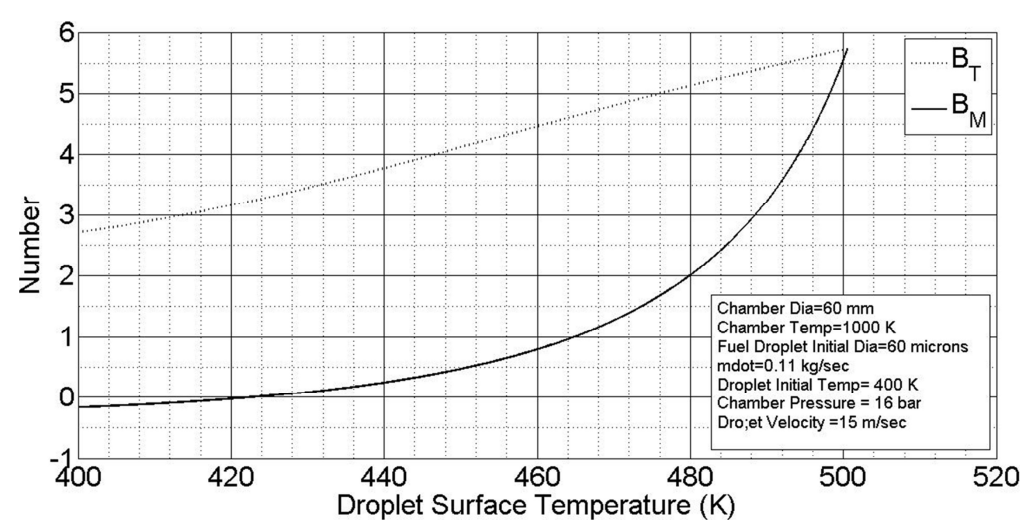

FIG. 2. END OF THE HEATING PHASE

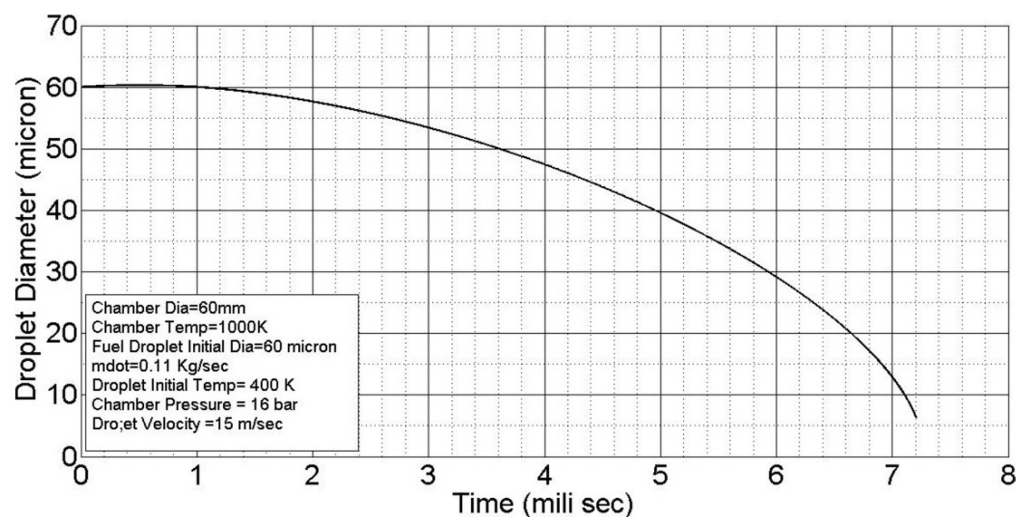

FIG. 3. KEROSENE DROPLET DIAMETER IN HEATING PHASE

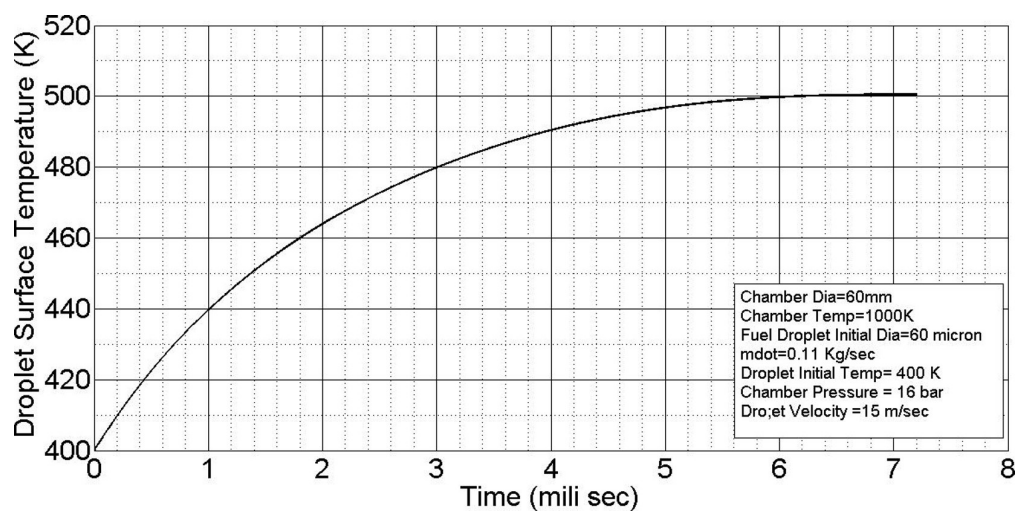

FIG. 4. KEROSENE DROPLET SURFACE TEMPERATURE IN HEATING PHASE 
Fig. 9 shows that effects of the combustion chamber diameter on characteristic length and relative velocity at fixed mass flow rate. When diameter of chamber increases for a given input condition then more area is available for hot gas to flow due to which velocity of hot gas decreases. Decrease in hot gas velocity causes decrease in relative velocity. Reynolds number, turbulent intensity and convection coefficient decreases. Decrease in turbulent intensity reduces heat and mass transfer, which consequently decreases rate of fuel droplet evaporation as long as relative velocity get zero.

Fig. 10 shows decrease in characteristic length with increase in fuel droplet initial temperature. Fuel droplet inlet temperature can be control in cooling jacket of the chamber but if it get boiled then it will damage inside wall of the chamber.

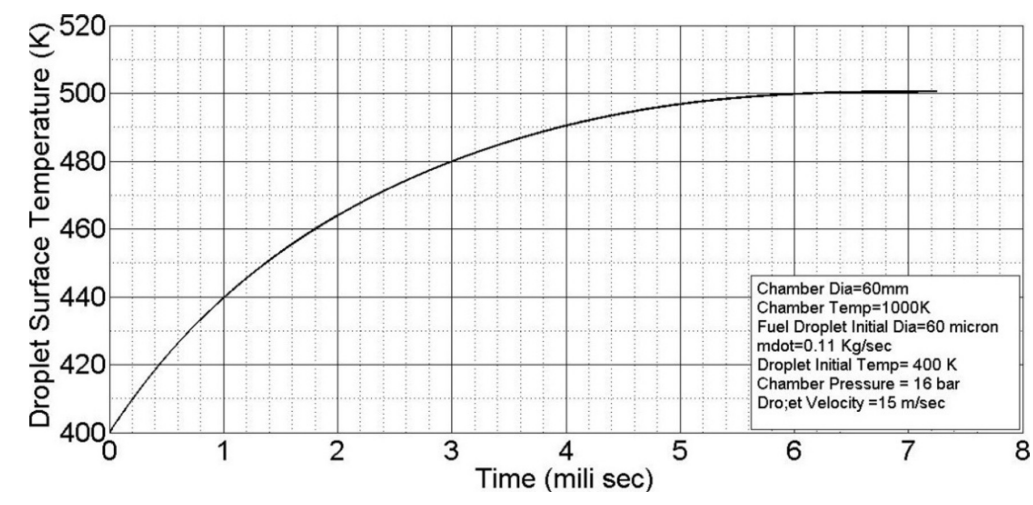

FIG. 5. FUEL SURFACE TEMPERATURE OF ALL OF IT LIFE TIME

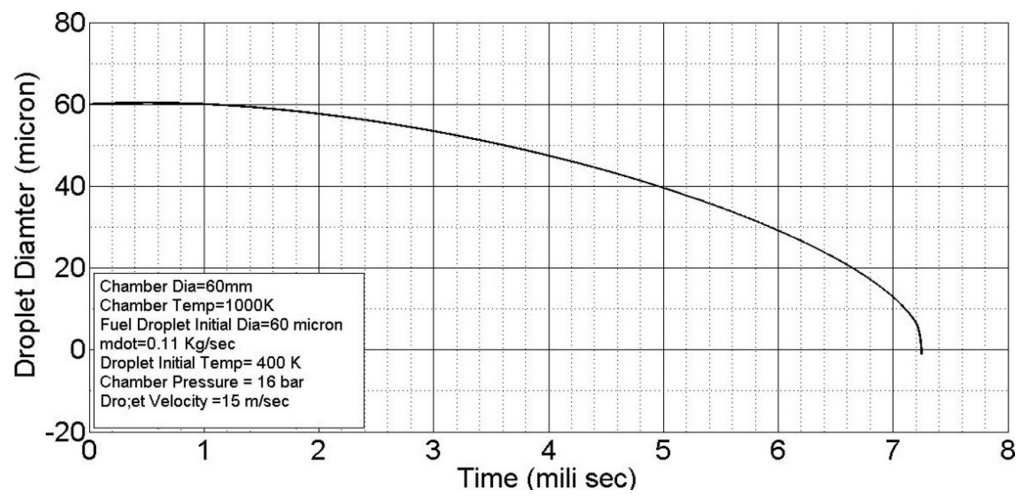

FIG. 6. FUEL DROPLET DIAMETER WITH TIME

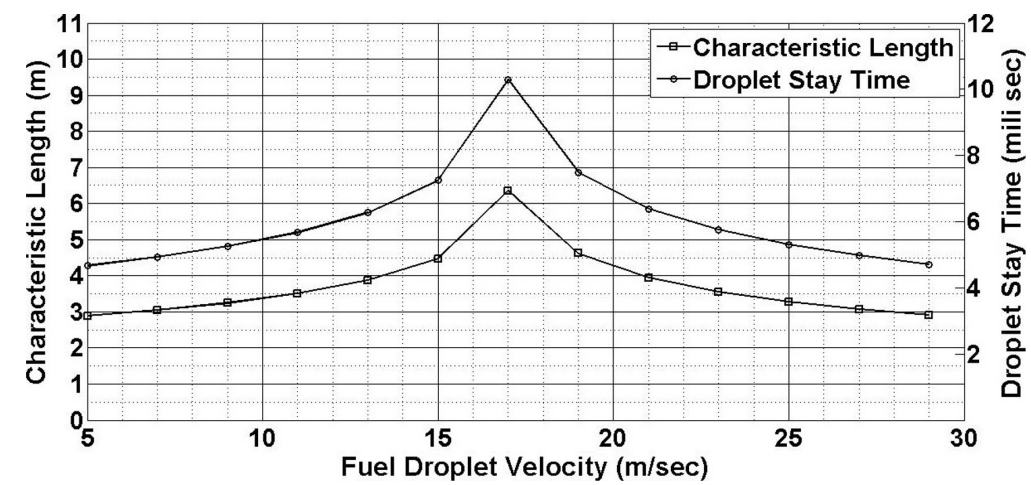

FIG. 7. EFFECTS OF DROPLET VELOCITY ON CHARACTERISTIC LENGTH 
Fig. 11 shows that requirement of volume increases with increase in mass flow rate up to a limit. As diameter of chamber is fixed therefore any increase in mass flow rate causes increase in gas velocity, Reynolds number and turbulent intensity. Increase in turbulent intensity helps in heat and mass transfer, which consequently increases rate of fuel droplet evaporation. Peak point is the point where relative velocity get zero. To keep same pressure and temperature of chamber, increase in throat area, is required which resultantly increases volume of chamber.

Fig. 12 show very less effects in the temperature range of 950-1050 K.

Fig. 13 shows that initially characteristic length is increasing with increase in combustion chamber temperature for chamber pressure of 8,10 and 12 bar but after getting a peak then it goes down with further increase in temperature. In case of 14 and 16 it decrease first then it start increasing but after a peak it goes down again with increase in chamber temperature. This peak in characteristic length shifts towards the right with increase in combustion chamber pressure. This shift is caused by increase in boiling point of fuel droplet. Fuel droplet vaporizes at higher temperature when combustion chamber pressure is high. Fuel droplet surface Temperature and reference temperature is also high at higher pressure. Properties of fuel are calculated at reference temperature and reference temperature is low at low combustion chamber temperature and pressure. As long as the reference temperature is below boiling point of fuel droplet then characteristic length requirement is increasing with increase in temperature. The characteristic

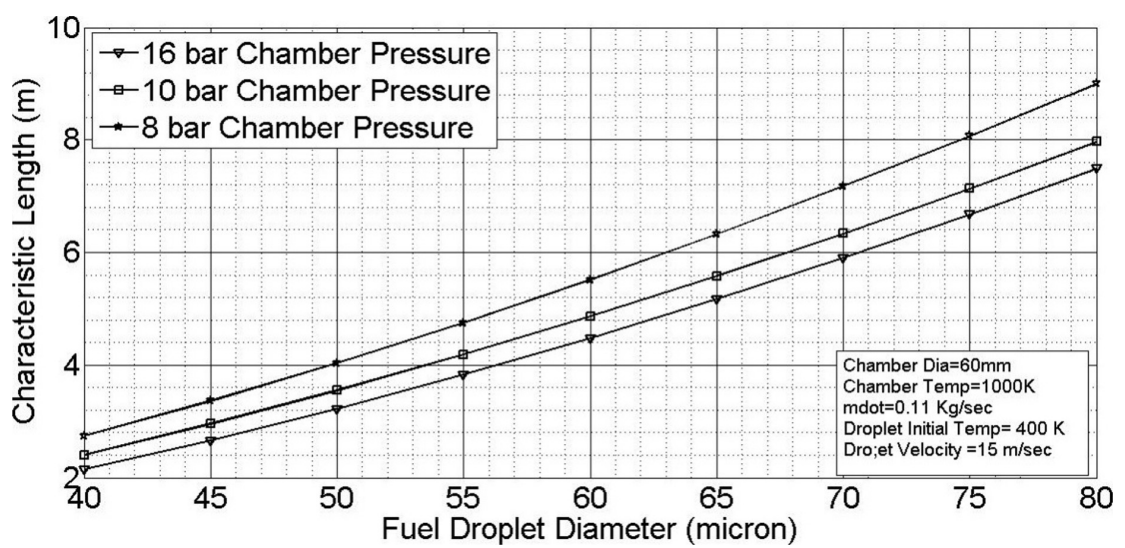

FIG. 8. EFFECTS OF CHAMBER PRESSURE ON CHARACTERISTIC LENGTH

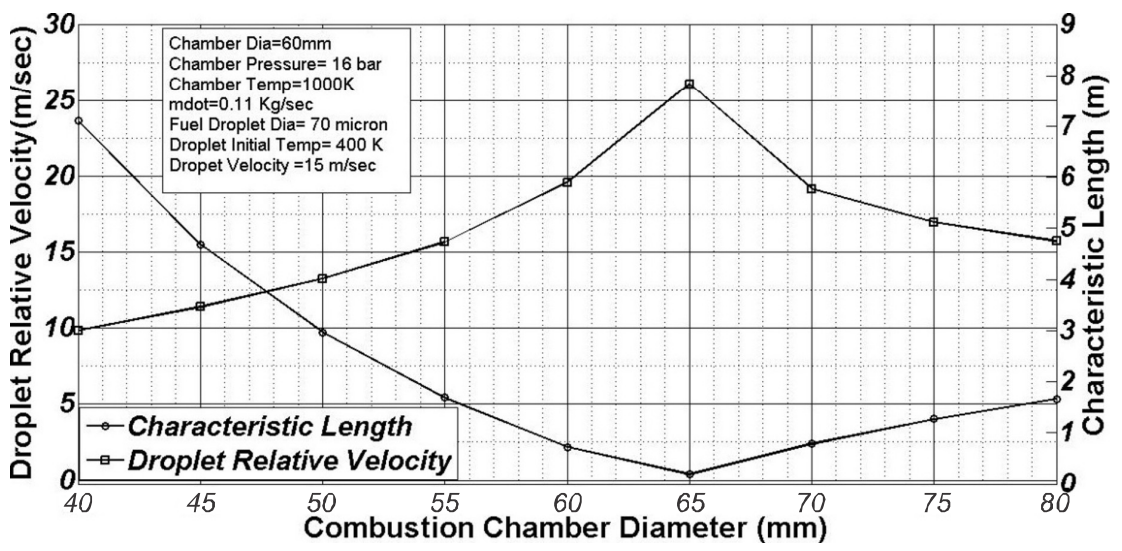

FIG. 9. EFFECT OF CHAMBER DIAMETER ON CHARACTERISTIC LENGTH

Mehran University Research Journal of Engineering \& Technology, Volume 38, No. 3, July, 2019 [p-ISSN: 0254-7821, e-ISSN: 2413-7219] 
length is decreasing with increase in combustion chamber temperature after peak of characteristic length because reference temperature is above boiling point of fuel droplet. This phenomenon is very important while designing gas generator but is not supposed to happen at higher temperature because reference temperature will be well above the critical point of fuel.
It is clear from Figs. 7-10 and Fig. 12 that at current applied input condition, minimum characteristic length is required at droplet velocity of $5 \mathrm{~m} / \mathrm{sec}$, droplet diameter of 40 microns, $0.056 \mathrm{~kg} / \mathrm{sec}$ mass flow rate, 16 bar pressure, $1050 \mathrm{~K}$ combustion chamber diameter of $40 \mathrm{~mm}$ and $400 \mathrm{~K}$ initial droplet temperature. Characteristic length calculated at these conditions is 0.8769 .

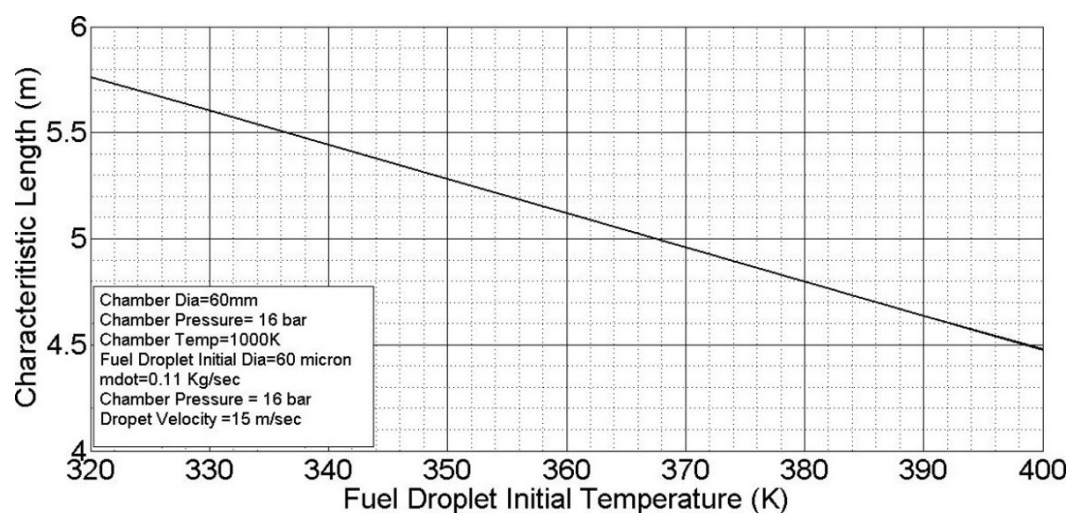

FIG. 10. DROPLET INITIAL TEMPERATURE EFFECTS ON CHARACTERISTIC LENGTH

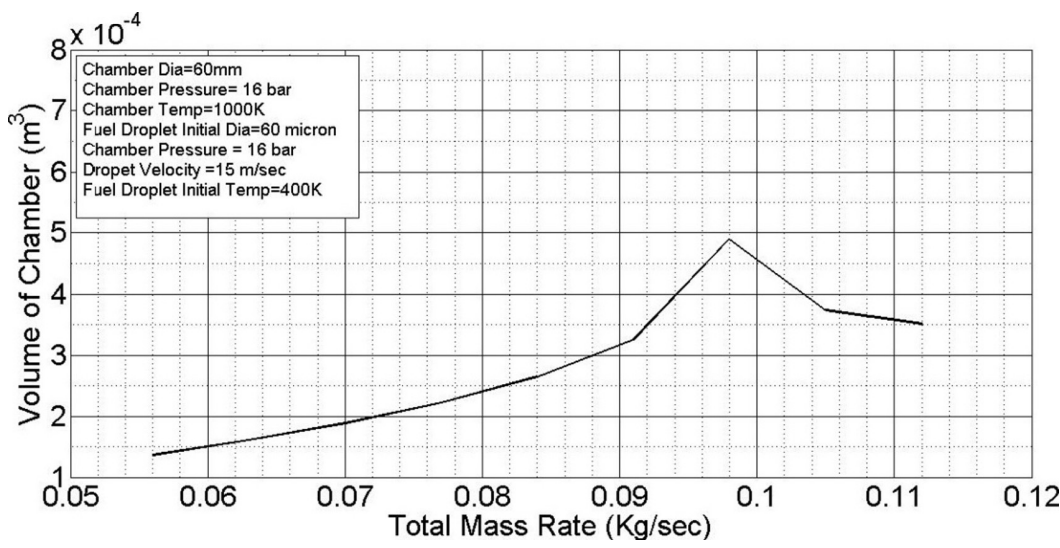

FIG. 11. MASS FLOW RATE EFFECTS ON CHARACTERISTIC LENGTH

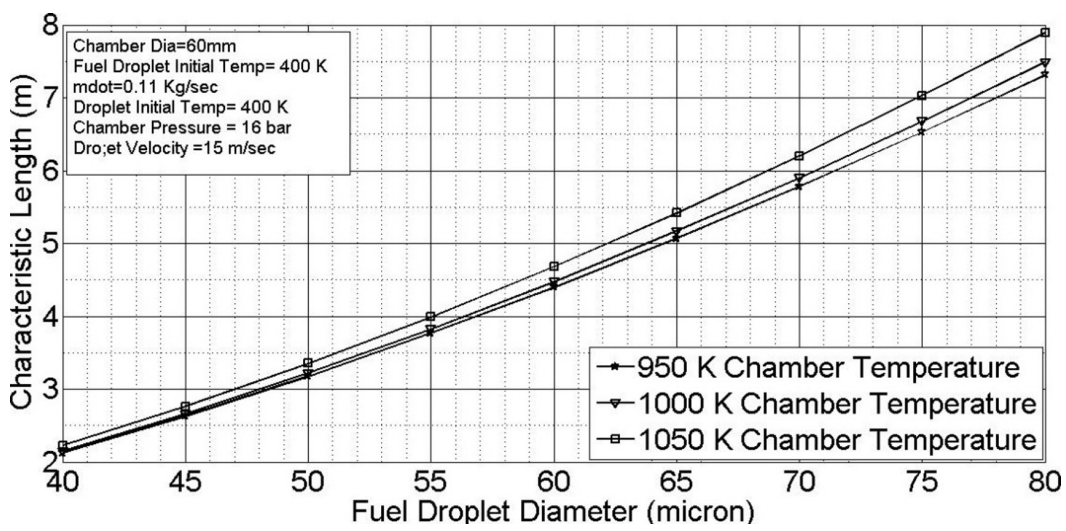

FIG. 12. EFFECT OF COMBUSTION CHAMBER TEMPERATURE ON CHARACTERISTIC LENGTH 


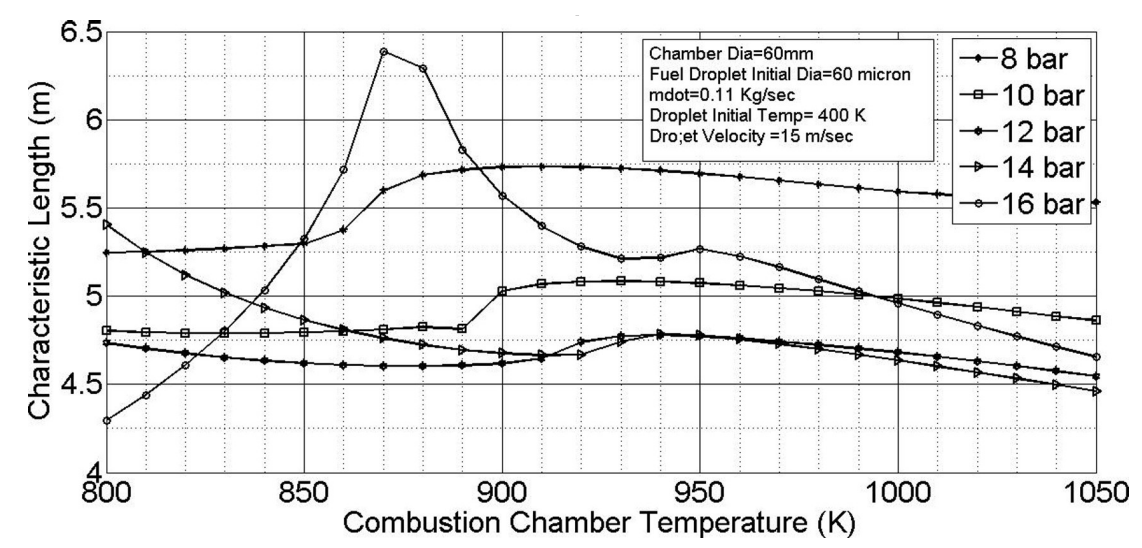

FIG. 13. CHAMBER PRESSURE AND TEMPERATURE EFFECTS ON CHARACTERISTIC LENGTH

\section{CONCLUSION}

The normal data available in literature showing characteristic length size with propellant combination is miss guiding and does not show full picture. Characteristic length is not only dependent on propellant combination but is dependent of many factors. The above discussion shows that fuel droplet diameter is more important. The effects of combustion chamber pressure, combustion chamber temperature, combustion chamber diameter are higher at higher fuel droplet diameter. Designer should take care of the boiling point of fuel droplet at that pressure while designing combustion chambers for lower temperature. Reference point should be higher than the boiling point of the fuel droplet at that pressure.

\section{NOMENCLATURE}

\footnotetext{
$\mathrm{A}_{\mathrm{t}} \quad$ Combustion chamber throat area $\left(\mathrm{m}^{2}\right)$

$\mathrm{B}_{\mathrm{M}} \quad$ Spalding mass transfer number

$B_{T} \quad$ Spalding heat Transfer Number

$\mathrm{D} \quad$ diameter $(\mathrm{m})$

$\bar{D} \quad$ Diffusion coefficient

$\mathrm{K}_{\mathrm{q}} \quad$ evaporation rate under quiescent condition $\left(\mathrm{m}^{2} / \mathrm{s}\right)$

$\mathrm{K}_{\mathrm{L}}$ evaporation rate under laminar flow condition $\left(\mathrm{m}^{2} / \mathrm{s}\right)$

$\mathrm{K}_{\mathrm{T}}$ evaporation rate under turbulent flow condition and zero mean velocity $\left(\mathrm{m}^{2} / \mathrm{s}\right)$

$\mathrm{K}_{\mathrm{TL}} \quad$ evaporation rate under turbulent flow condition with mean velocity $\left(\mathrm{m}^{2} / \mathrm{s}\right), \mathrm{K}_{\mathrm{TL}}=\mathrm{K}_{\mathrm{T}} \mathrm{K}_{\mathrm{L}}$

$\mathrm{L}^{*} \quad$ characteristic length of combustion chamber (m)

$\mathrm{L} \quad$ latent heat of vaporization $(\mathrm{J} / \mathrm{Kg})$
}

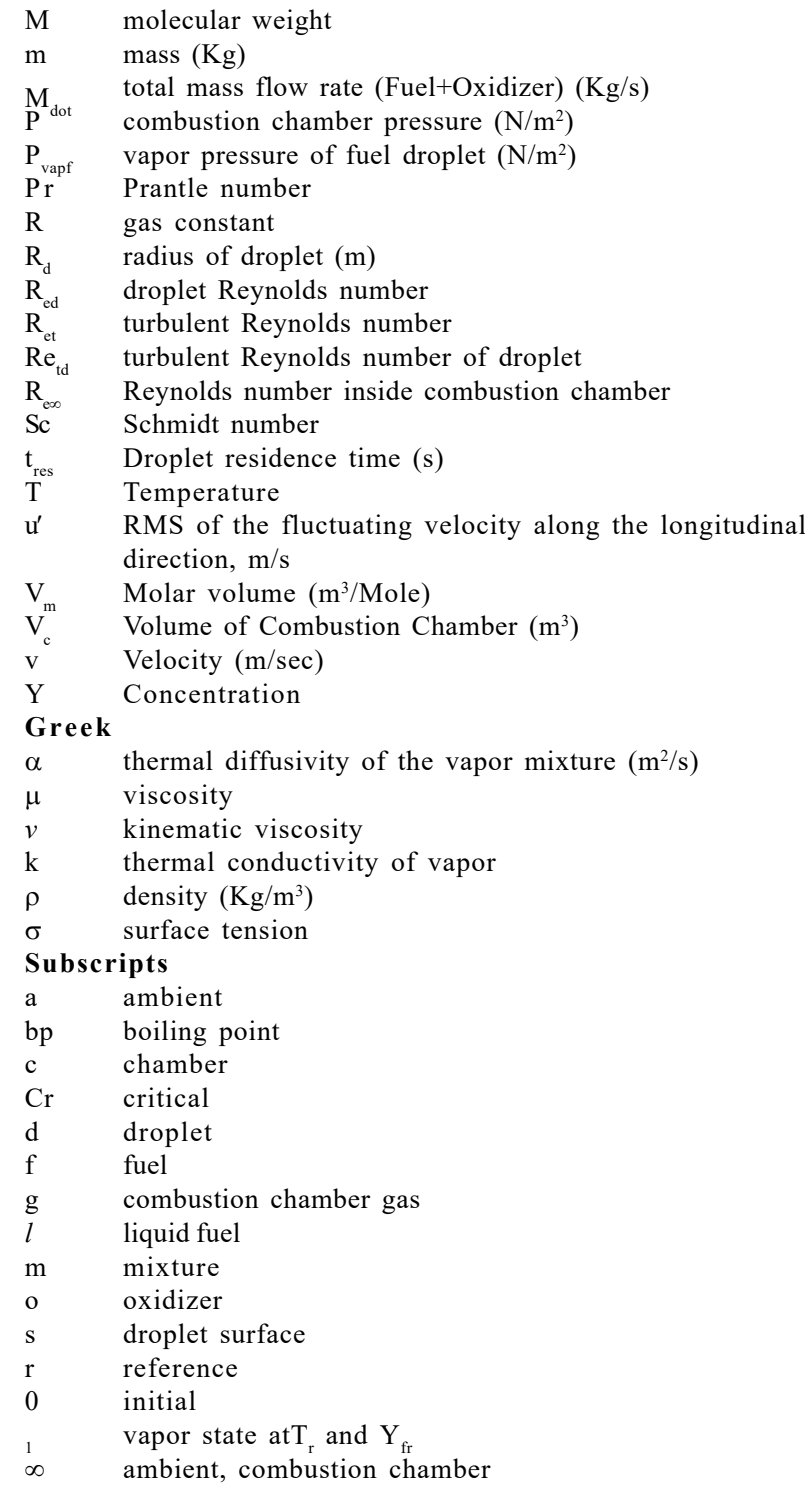




\section{ACKNOWLEDGMENT}

The authors gratefully acknowledge the support of the Library staff, Institute of Space Technology, Islamabad, Pakistan, for providing required literature.

\section{REFERENCES}

[1] Sutton, G., and Biblarz, O., "Rocket Propulsion Elements", John Wiley \& Sons, Canada, 2001.

[2] Huang, D.K., and Huzel, D.H., "Design of Thrust Chambers and Other Combustion Devices",Modern Engineering for Design of Liquid-Propellant Rocket Engines, American Institute of Aeronautics and Astronautics, pp. 67-134, 1992

[3] Humble, R., "Space Propulsion Analysis and Design", The McGraw-Hill Companies, 1995.

[4] Mulkey, H.W., Moser, M.D., and Hitt, M.A., "GOX/ Methane Combustion Efficiency of a Swirl Coaxial Injector", 45th AIAA/ASME/SAE/ASEE Joint Propulsion Conference \& Exhibit, Denver, Colorado, 2-5 August, 2009.

[5] Jo, S., An, S., Kim, J., Yoon, H., and Kwon, S., "Performance Characteristics of Hydrogen Peroxide/ Kerosene Staged-Bipropellant Engine with Axial Fuel Injector," Journal of Propulsion and Power, Volume 27, No. 3, pp. 684-691, May, 2011.

[6] Kim, J.S., Jung, H., Bae, S.H., Bae, D.S., and Kim, J.H., "Performance Evaluation of a $70 \mathrm{~N}$ Hydrazine Thruster According to the Variation of Characteristic Length", $51^{\text {st }}$ AIAA/SAE/ASEE Joint Propulsion Conference, American Institute of Aeronautics and Astronautics, Virginia, 2015.

[7] Son, M., Koo, J., Cho, W.K., and Lee, E.S., "Conceptual Design for a Kerosene Fuel-Rich Gas-Generator of a Turbopump-Fed Liquid Rocket Engine", Journal of Thermal Science, Volume 21, No.5, pp. 428-434, 2012.

[8] Birouk, M., and Gökalp, I., "Current Status of Droplet Evaporation in Turbulent Flows", Progress in Energy and Combustion Science, Volume 32, No.4, pp. 408-423, 2006.
[9] Kim, H., and Sung, N., "The Effect of Ambient Pressure on the Evaporation of a Single Droplet and a Spray", Combustion and Flame, Volume 135, No. 3, pp. 261-270, 2003.

[10] Sirignano, W., "An Integrated Approach to Spray Combustion Model Development", Combustion Science and Technology, Volume 58, No. 1-3, pp. 231-251, 1988

[11] Sirignano, W., "The Formulation of Spray Combustion Models, Resolution Compared to Droplet Spacing", Journal Heat Transfer, Volume 108, No. 3, pp. 633, 1986.

[12] Faeth, G., "Current Status of Droplet and Liquid Combustion", Progress in Energy and Combustion Science, Volume 3, No.4, pp. 191-224, 1977.

[13] Law, C., "Recent Advances in Droplet Vaporization and Combustion", Progress in Energy and Combustion Science, Volume 8, No. 3, pp. 171-201, 1982.

[14] Wang, Z.G. ,'Internal Combustion Processes of Liquid Rocket Engines Modeling and Numerical Simulations", John Wiley \& Sons, Singapore, 2016.

[15] Godsave, G., "Studies of the Combustion of Drops in a Fuel Spray-The Burning of Single Drops of Fuel", Symposium (International) on Combustion, Volume 4, No. 1, pp. 818-830, 1953.

[16] Froessling, N., "The Evaporation of Falling Drops", UKAEA Research Group, Atomic Energy Research Establishment, 1968.

[17] Faeth, G.M., "Evaporation and Combustion of Sprays", Progress in Energy and Combustion Science, Volume 9, No. 1-2, pp. 1-76, 1983.

[18] Birouk, M., Abou Al-Sood, M.M., and Gokalp, I., "Droplet Evaporation in a Turbulent Environment at Elevated Pressure and Temperature Conditions", Combustion Science and Technology, Volume 180, No. 10-11, pp. 1987-2014, 2008.

[19] Maisel, D.S., and Sherwood, T.K., "Effect of Air Turbulence on Rate of Evaporation of Water", Chemica Engineering Progress, Volume 46, No.4, pp. 172-175, 1950. 
[20] Hsu, N.T., and Sage, B.H., "Thermal and Material Transfer in Turbulent Gas Streams: Local Transport from Spheres", AIChE Journal, Volume 3, No. 3, pp. 405-410, 1957

[21] Gökalp, I., Chauveau, C., Simon, O., and Chesneau, X., "Mass-Transfer from Liquid Fuel Droplets In TurbulentFlow", Combustion and Flame, Volue 89, pp. 286-298, 1992.

[22] Wu, J.S., Liu, Y.J., and Sheen, H.J., "Effects of Ambient Turbulence and Fuel Properties on the Evaporation Rate of Single Droplets", International Journal of Heat and Mass Transfer, Volume 44, No. 3, pp. 4593-4603, 2001.

[23] Wu, J.S., Hsu, K.H., Kuo, P.M., and Sheen, H.J., "Evaporation Model of a Single Hydrocarbon Fuel Droplet Due to Ambient Turbulence at Intermediate Reynolds Numbers", International Journal of Heat and Mass Transfer, Volume 46, No. 24, pp. 4741-4745, 2003.

[24] Hiromitsu, N., Kawaguchi, O., and Hiromitus, N., "Influence of Flow Turbulence on the Evaporation Rate of a Suspended Droplet in a Hot Air Flow", Heat Transfer Japanese Research, Volume 24, No. 8, pp. 689-700, 1995.

[25] Birouk, M., and Gokalp, I., "A New Correlation for Turbulent Mass Transfer from Liquid Droplets", International Journal of Heat and Mass Transfer, Volume 45, No. 1, pp. 37-45, 2002.
[26] Reid, R.C., Prausnitz, J.M., and Poling, B.E., “The Properties of Gases and Liquids”, McGraw-Hill, 1987.

[27] Skinner, L.M., and Sambles, J.R., "The Kelvin Equation-A Review",Journal of Aerosol Science, Volume 3, No. 3, pp. 199-210, 1972.

[28] Kleinstreuer, C., Shi, H., and Zhang, Z., "Computational Analyses of a Pressurized Metered Dose Inhaler and a New Drug-Aerosol Targeting Methodology",Journal of Aerosol Medicine: The Official Journal of the International Society for Aerosols in Medicine, Volume 20, No.3, pp. 294-309, 2007.

[29] Sazhin, S.S., Kristyadi, T., Abdelghaffar, W.A., and Heikal, M.R., "Models for Fuel Droplet Heating and Evaporation: Comparative Analysis", Fuel, Volume 85, No. 12-13, pp. 1613-1630, 2006

[30] Yearling, P.R., "Experimental Determination of Convective Heat and Mass Transfer Rates from Single Evaporating Droplets in a Turbulent Air Flow", North Carolina State University, 1995.

[31] "FLUENT 6.3 User's Guide - 7.2.2 Determining Turbulence Parameters", [Online]Available: https:// www.sharcnet.ca/Software/Fluent $6 / \mathrm{html} / \mathrm{ug} /$ node217.htm. [Accessed: 6the March, 2017]. 